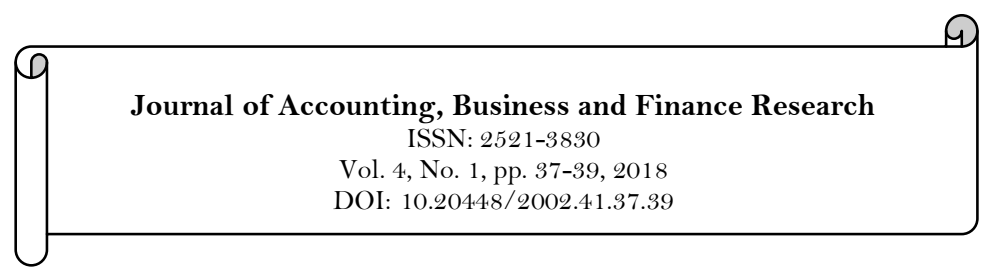

\title{
Simulating the Case against Stock Picking
}

\section{Charles J. Higgins ${ }^{1}$}

${ }^{1}$ Dept. Finance/CIS Loyola Marymount Univ. 1 LMU Dr. Los Angeles, CA 90045-8385, USA. Email:chiggins@lmu.edu

\begin{tabular}{|c|c|}
\hline Abstract & \\
\hline $\begin{array}{l}\text { In simulating a portfolio of } 100 \text { security prices the median terminal } \\
\text { price was regularly below that of the average mean portfolio price. } \\
\text { In that picking a single security would likely choose the median } \\
\text { terminal price, a case can be made against stock picking. }\end{array}$ & $\begin{array}{l}\text { Keywords: } \\
\text { Stocks } \\
\text { Normal distribution } \\
\text { Skewed distribution } \\
\text { Security } \\
\text { Standard deviation } \\
\text { Investment } \\
\text { Stock market } \\
\text { Portfolio } \\
\text { Stock picking } \\
\text { Diversification. } \\
\text { JEL Classification: } \\
\text { C60 Mathematical and } \\
\text { Simulation Modeling. } \\
\text { Licensed: } \\
\text { This work is licensed under a } \\
\text { Creative Commons Attribution } \\
\text { 4.0 License. } \\
\text { Publisher: } \\
\text { Scientific Publishing Institute }\end{array}$ \\
\hline
\end{tabular}

\section{Introduction}

Notwithstanding the body of evidence that holding a diversified no-load low expense ratio mutual fund or exchange traded fund is the most efficacious choice toward maximal portfolio returns (see (Edwin, Gruber, Das, \& Hlavka, 1993; Elton \& Martin, 1995; Lorie \& Mary, 1973)) many individuals still think that a possibility exists to beat the market.

\section{Simulation}

Simulated index portfolios were created and their average mean returns were compared to the most likely cases of the median securities chosen there from. The simulations in order to be realistic had monthly standard deviations of 2,3 , and 4 percent and thus yearly standard deviations of 6.9, 10.4, 13.9 percent respectively (square root of the 12 months times the monthly return). Each monthly price was determined from the prior month's price by:

$$
\mathrm{P}_{\mathrm{t}}=\mathrm{P}_{\mathrm{t}-1}(1+\mathrm{s} \sigma) \text { where } \sigma=\left(-2 \ln \left(\check{\mathrm{r}}_{1}\right)\right)^{1 / 2} \sin \left(2 \pi \check{\mathrm{r}}_{2}\right)
$$

and that $\breve{\mathrm{r}}=\mathrm{U}(0,1)$ or $=\mathrm{RAND}()$ in Excel or $\mathrm{RND}(1)$ in Basic and $\mathrm{s}$ is the monthly standard deviation.

\section{Results}

The simulation produced a more realistic security price distribution with no negative prices and the possibility that some extraordinary high priced securities may result. Here's a graphic from previous simulations: 


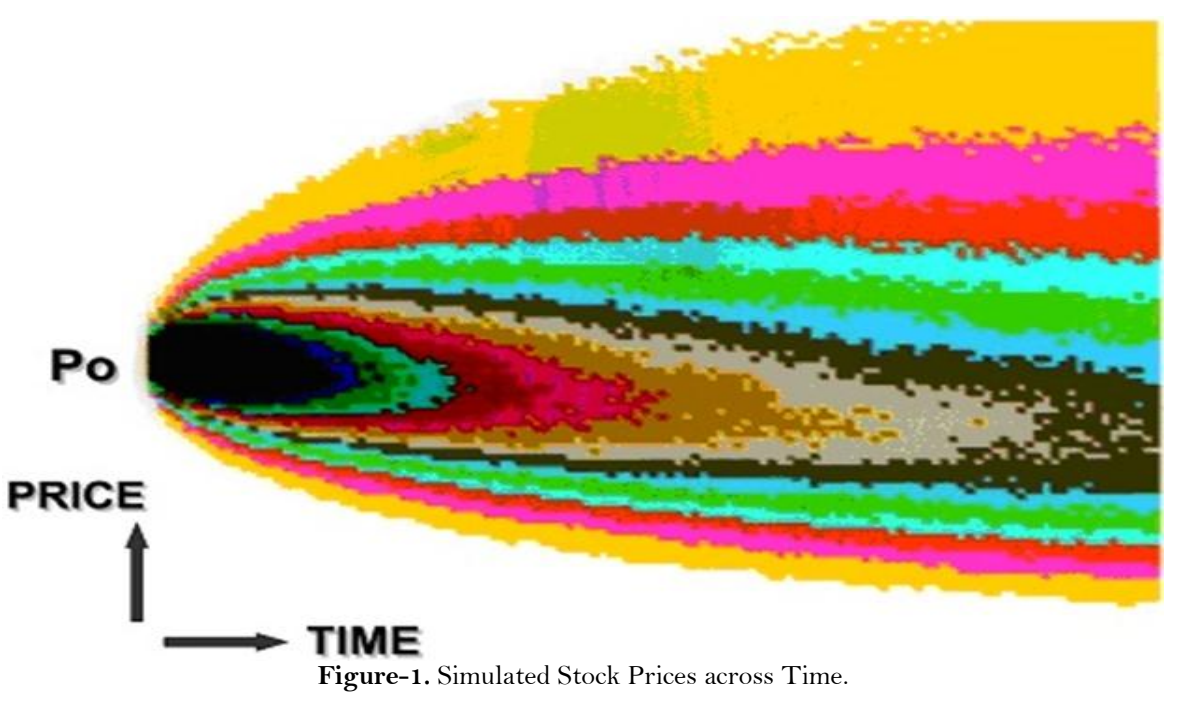

A portfolio of 100 security prices was simulated across 12 months with 1000 simulated runs each. The results showed that the median terminal price of a single selected security was regularly below that of the average mean portfolio price.

\section{The results of three independent simulated runs of 1,000:}

$\begin{array}{cccc}\begin{array}{c}\text { Std. Deviaton } \\ \text { Monthly }\end{array} & \begin{array}{c}\text { Mrly. } \\ \text { Above }\end{array} & \begin{array}{c}\text { Average } \\ \text { Difference }\end{array} \\ 2 \% & 6.9 \% & 12 & 1.19 \% \\ 3 & 10.4 & 25 & 1.49 \\ 4 & 13.9 & 28 & 1.90\end{array}$

In a simulation of 1000 runs with a .02 monthly standard deviation there were 12 cases when the median selected security beat the portfolio mean with an average 1.19 percent lower difference between the two. For an independent run with a .03 monthly standard deviation there were 25 cases when the median beat the portfolio mean average with an average differential of 1.49 percent below the portfolio average. With another run with a .04 percent monthly standard deviation there were 28 cases when the median beat the portfolio average with an average differential of 1.90 percent below the portfolio average.

\section{Conclusion}

Thus one should be able to conclude that picking a single security would likely beat the market is unlikely and moreover adds to the evidence against stock picking (see (Bodie, Alex, \& Alan, 2001; Higgins, 2013)). In addition, while the classic approach here is to minimize risk (see (Markowitz, 1959)), it seems appropriate here to also note that in holding a diversified index portfolio that one is more likely to achieve a superior return as well as minimize risk. Furthermore (and not generally observed) in holding a diversified index portfolio one always includes the otherwise difficult to select stellar superior winners. And unlike other gambles, the return to the stock market is generally positive. That is to say while betting on black and red in say roulette that one would on average lose, that holding the entire portfolio with an average positive return one tends to win and more so as costs are lowered with lower expense ratios and load charges. See/hear also my YouTube/DrCinvests video (Higginss, 2018).

Of course it is no surprise given that the security price distribution here as well as the case generally in the real world is asymmetric and that one would expect the median to be below that of the mean (see Investopedia). Consider: 


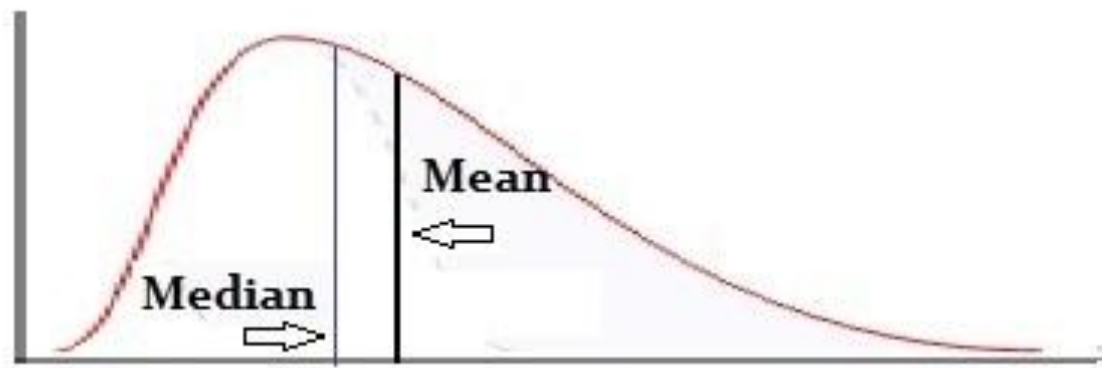

Right skewed distribution: Mean is to the right

\author{
Figure-2. Asymetric Security Price Distribution. \\ Statistics How To: Statistics for the Rest of Us!
}

\title{
5. Computer Program
}

Here's the Basic computer program:

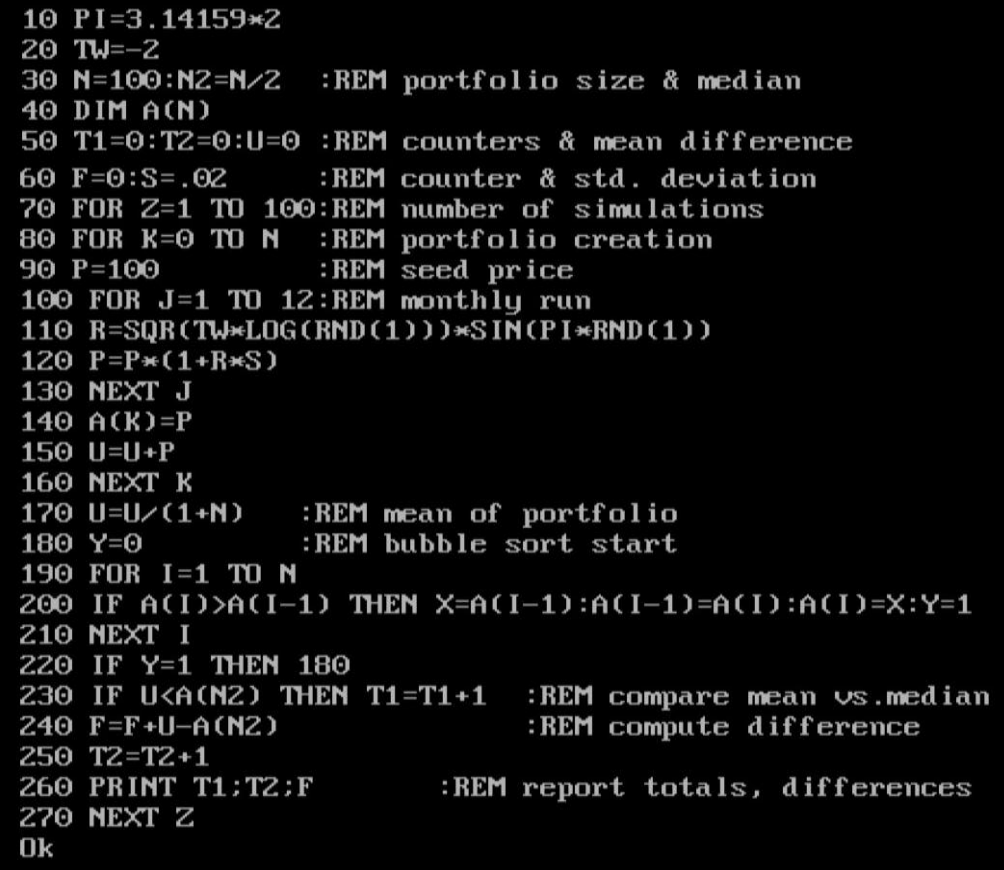

\section{References}

Bodie, Z., Alex, K., \& Alan, J. M. (2001). Essentials of investments (10th ed.). Boston: McGraw-Hill Irwin.

Edwin, J. E., Gruber, M. J., Das, S., \& Hlavka, M. (1993). Efficiency with costly information: A reinterpretation of evidence from managed portfolios. Review of Financial Studies, 6(1), 1-22.

Elton, E. J., \& Martin, J. G. (1995). Modern portfolio theory and investment analysis (5th ed.). New York: John Wiley \& Sons. Higgins, C. (2013). The case against stock picking. International Research Journal of Applied Finance, 4(10), 1346-1353.

Higginss, C. (2018). Simulating the case against stock picking YouTube/DrCinvests. Retrieved from https://www.youtube.com/watch?v=mkl-tyqqZyI.

Lorie, J. H., \& Mary, T. H. (1973). The stock market, theories and evidence. Homewood, Illinois: Richard D. Irwin, Inc. Markowitz, H. (1959). Portfolio selection: Efficient diversification of investments. New York: John Wiley. 